similar to that found in Toronto $(14 \%)^{6}$ but lower than figures in America (20\% in California ${ }^{3}$ ) and higher than those in Hawaii $(0 \%)^{6}$ and Queensland $(5 \%) .^{+}$

Although fixed dilated pupils on admission are not a reliable predictor of outcome after a serious submersion incident, the pupillary reflex is unaffected by the drugs given to electively ventilated paralysed patients and is thus a useful indicator of outcome during this form of treatment. All children who fully recovered had normal sustained pupil reactivity within six hours after starting cardiopulmonary resuscitation. A longer period before the onset of pupil reactivity and the recurrence of periods of fixed dilated pupils was associated with neurological deficit or death.

Respiratory effort is probably the most sensitive prognostic sign on admission in the unconscious nearly drowned child: all children with established respiration in our study made a full recovery. Nevertheless, especially in the very hypothermic children, absence of respiratory effort does not necessarily predict a poor outcome. Prolonged, poorly controlled fits beyond the first day after admission to hospital were associated with neurological deficit. This agrees with the findings of Conn and Barker ${ }^{6}$ that late poor electroencephalographic traces are associated with a poor outcome.

Why should some patients apparently dead on admission with fixed dilated pupils survive normally? It has been suggested that this is because of the diving reflex, which is more pronounced in children than adults, in which the peripheral circulation is shut down with a profound bradycardia, the brain achieving most of the circulation. ${ }^{1+}$ Other work, however, suggests that the diving reflex is not active in humans ${ }^{15}$ and submersion hypothermia is more likely to account for some people surviving prolonged periods under water. The rapid fall in body temperature on immersion in cold water exerts protective cranial hypothermia before the circulation fails. ${ }^{16}$ Orlowski used the term ice water drowning" as a review of published reports showed that all the cases with a good outcome after prolonged immersion occurred in water of temperature $\leqslant 10^{\circ} \mathrm{C}$. The protective effect of hypothermia would be more pronounced in children than in adults because children have a higher surface area to body weight ratio and therefore cool more rapidly. Most outdoor drownings in the United Kingdom are in water temperatures of $<20^{\circ} \mathrm{C}$; four of the children in our series who survived normally with fixed dilated pupils and no respiratory effort had body temperatures less than $32^{\circ} \mathrm{C}$ and three were profoundly hypothermic.

We thank the British Paediatric Surveillance Unit; all the consultant paediatricians who returned cards and gave us details of their patients; the Welsh Scheme for Social and Medical Research for funding; the Child Accident Prevention Trust for encouragement; and, in particular, Jim Nixon from the Department of Child Health, Brisbane, Australia, for support at the start of the project. We thank all Her Majesty's Coroners and procurators fiscal, the Royal Society for Prevention of Accidents, the Office of Population Censuses and Surveys, the Scottish Government Record Office, the Irish Government Statistical Office, and the Northern Irish Office for information.

1 Office of Population Censuses and Surveys. Deaths by cause: 1988 registrations. OlC:S Monitor 1989. (DH 2)

2 O'Carroll PW, Alkon E, Weiss B. Drowning mortality in Los Angeles county 1976 to 1984. FAMA 1988;260:380-3.

3 Peterson B. Morbidity of childhood near drowning. Pediatrics 1977;59:364-70.

4 Pearn J. Neurological and psychometric studies in children surviving fresh water immersion accidents. Lancet 1977; i: 7-9.

5 Pearn J, Bart RD, Yamoaka R. Neurological sequelae after childhood near drowning: a total population study from Hawaii. Pediatrics 1979;64:187-90. 6 Conn AW, Barker GA. Fresh water drowning and near drowning: an update. Canadiun Anaesthetist Society fournal 1984;31:S38-44.

Modell JH, Graves SA, Ketover A. Clinical course of 91 consecutive near drowning victims. Chest 1976;70:231-8.

8 Frates RC. Analysis of predictive factors in the assessment of warm water near drowning in children. Am $\mathcal{f}$ Dis Child 1981;135:1006-8.

Orlowski JP. Drowning, near drowning and ice water drowning. $y_{A M A}$ 1988:260:390-1.

10 Modell JH. Drown versus near-drown: a discussion of definitions. Crit Care Med 1981:9:351-2.

11 Frewen TC, Sumbat WO, Han VK, Amacher AL, Del Maestro RF, Sibbald $\mathrm{W}^{\prime} \mathrm{F}$. Cerebral resuscitation therapy in paediatric near drowning. 9 Pediat 1985;106:615-7.

12 Pearn JH. The management of near drowning BMF 1985;291:1447-52.

13 Pearn JH, De Buse P, Mohay H, Golden M. Sequential intellectual recovery after near drowning. Med $\mathcal{F}$ A ust 1979;1:463-4.

14 Golden F. Problems of immersion. Br f Hosp Med 1980;23:373-6.

15 Ramey CA, Ramey DN, Hayward JS. Dive response of children in relation to cold water drowning. 7 Appl Physiol 1987;63:665-8.

16 Harries M. Drowning and near drowning. BM7 1986;293:123-4.

\title{
Epilepsy: disappearing lesions appearing in the United Kingdom
}

\author{
A Kennedy, F Schon
}

\section{Abstract}

Objective-Investigation of spontaneously resolving lesions associated with epilepsy.

Design-Observational study during one year.

Setting-One neurology department.

Patients -4 cases in patients (one of Indian parents, one African, one white English, and one Afro-Caribbean) resident in the United Kingdom, who presented with transient epilepsy.

Main outcome measures-Findings on computed tomography and on screening for infections.

Results - In all four cases a small mass lesion in one cerebral hemisphere was observed on computed tomography, which resolved after $9,4,3$ and 1.5 months respectively without surgery.

Conclusions - The number of cases seen in one year suggests that the lesions may be more common in the United Kingdom than previously recognised and that research into their cause is warranted.

\section{Introduction}

In the United Kingdom only about $8 \%$ of adults with epilepsy of recent onset have mass lesions on computed tomography of the brain. Almost all of these lesions, however, are due to cerebral tumours; infectious and granulomatous masses are rare. In contrast, in India up to $40 \%$ of such patients have solitary, small, contrast enhancing, lesions in the cerebral hemisphere. ${ }^{1+4}$ The remarkable feature of these lesions is that most undergo spontaneous resolution within six months. The cause of these "disappearing" lesions remains controversial. An infectious aetiology is most likely; current evidence favours cysticercosis ${ }^{56}$ rather than an isolated tuberculoma. 'It is not clear why similar cases have so rarely been reported outside India. ${ }^{78}$ In this paper four such cases are described in patients who presented to our unit during the past year, suggesting that they may be commoner in Britain than previously recognised.

\section{Case reports}

Case 1-A 16 year old boy of Indian parents, who had been born in Ireland and who had lived exclusively in Ireland and England except for two periods of three months in India at ages 6 and 15, presented after a single tonic-clonic seizure. There were no physical abnormalities, and the only abnormal finding was in 


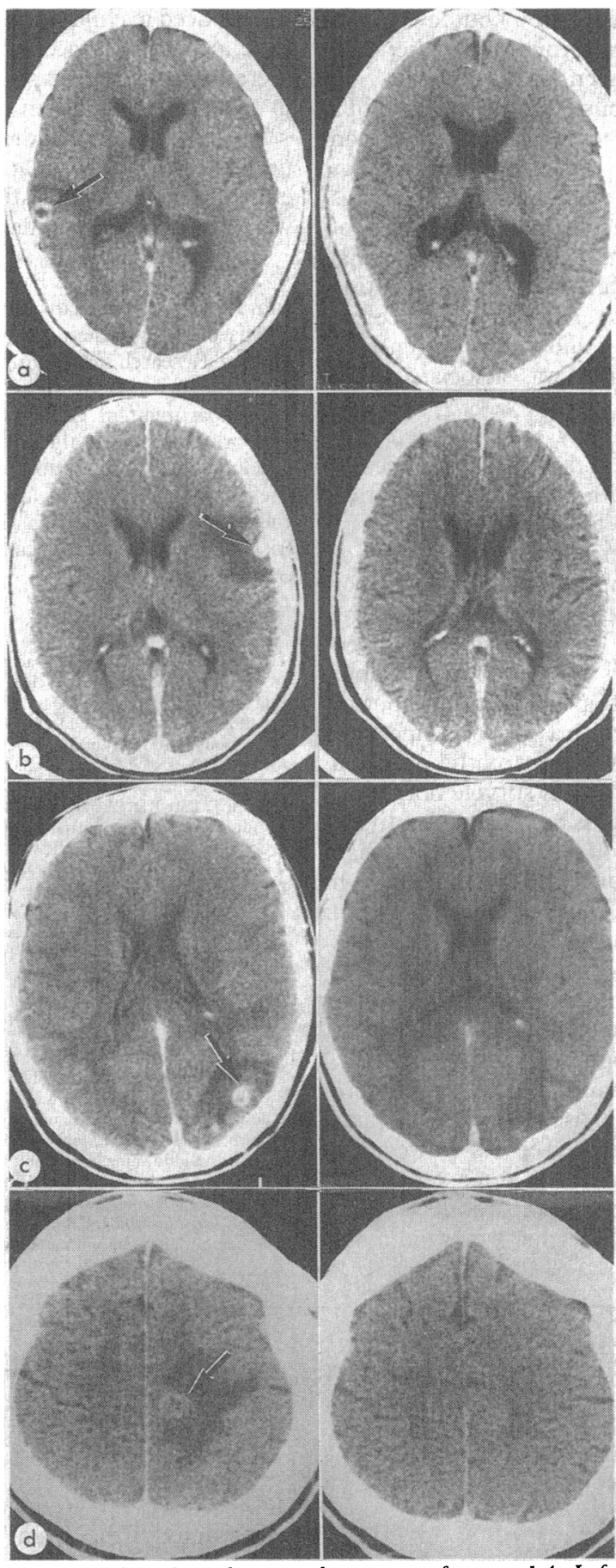

$a-d-C o n t r a s t$ enhanced computed tomograms for cases 1-4. Left: solitary, contrast enhancing lesion at presentation (arrowed). Right: complete resolution of lesion after $9,4,3$, and 1.5 months respectively (note: images reversed)

the computed tomogram of the brain, which showed a right parietal mass (figure, a). He was treated with antituberculous drugs for nine months, after which a repeat scan showed complete resolution of the lesion (figure).

Case 2-A 32 year old African, born in Zimbabwe, who had lived in Britain for 10 years, presented after three tonic-clonic seizures within two weeks. There were no abnormal findings except in the computed tomogram, which disclosed a left temporal lobe lesion (figure, b). After four months of treatment with anticonvulsant and antituberculous drugs a repeat tomogram showed that the lesion had resolved (figure). All treatment was withdrawn after nine months.

Case 3-A 21 year old white English man without any history of travel outside Europe presented after a single tonic-clonic seizure. Physical examination was unremarkable, and the sole abnormality was detected on computed tomography, which showed a left occipital lobe lesion associated with extensive cerebral oedema (figure, c). A further scan after four weeks showed considerable resolution, and complete resolution had occurred after 12 weeks. He was treated exclusively with phenytoin for one year.

Case 4-A 32 year old Afro-Caribbean man born in Guyana, who had lived in Britain since the age of 4, presented with a 10 week history of attacks of transient right sided numbness starting in the leg and spreading upwards into the trunk, arm, and then face. Each episode lasted three minutes; they were presumed to be due to sensory epilepsy. Computed tomography of his brain showed a left parietal lobe lesion (figure, d), and his cerebrospinal fluid contained 10 lymphocytes $/ \mathrm{ml}$. Despite receiving no treatment his attacks stopped after a further three weeks, the computed tomogram showed considerable resolution after six weeks, and repeat examination of his spinal fluid was unremarkable.

\section{Discussion}

These four cases, which closely resemble over 200 cases reported from India, all had negative investigations of blood and spinal fluid for likely infections, including tuberculosis, toxoplasmosis, cysticercosis, cryptococcosis, and HIV infection. Results of tests for sarcoidosis and multiple sclerosis were negative. Although multiple sclerosis can also cause spontaneously resolving lesions, these are normally situated deep in cerebral white matter rather than in superficial grey matter and the disease rarely presents with epilepsy.

The evidence implicating cysticercus as the aetiological agent is as follows. Firstly, in one series of 15 excision biopsy specimens of similar lesions cysticercosis was found in seven cases. ${ }^{5}$ Secondly, serological investigations in a series of 35 patients were positive for cysticercosis in $12 .^{6}$ Thirdly, computed tomographic studies in areas of endemic cysticercosis in South and Central America have shown two major patterns: patients with longstanding disease, who usually have multiple calcified cysts, and patients thought to have an acute lesion, many of whom present with epilepsy and have a solitary lesion similar to the disappearing lesions common in India. ${ }^{9}$ Of course, more than one aetiological agent may cause these lesions. An early study implicated tuberculosis because $25 \%$ of patients had active extracranial tuberculosis at the time of presentation.

Clearly it is vital to try and identify this subgroup of patients despite being currently unable to arrive at a definite diagnosis because in these patients, in contrast with most patients with cerebral space occupying lesions, early neurosurgical intervention is not indicated. This subgroup should initially be treated with anticonvulsant drugs alone. If significant spontaneous resolution has not occurred after three months further medical treatment with drugs active against cysticercosis or tuberculosis needs to be considered as well as stereotaxic biopsy. We hope that a wider awareness of this fascinating clinical problem will help both in patient management and in stimulating further research into its causes.

We thank Mr Uttley and Drs Monro and McKeran for permission to report their cases, and Mrs Sharon Frank for expert secretarial help.

1 Wadia RS, Makhale CN, Kelkar AV, Grant KB. Focal epilepsy in India with special reference to lesions showing ring or disc-like enhancement on contrast computed tomography. F Neurol Neurosurg Psychiatry 1987;50:1298-301.

2 Bansal BC, Abha Dua, Gupta R, Gupta MS. Appearing and disappearing CT scan abnormalities in epilepsy in India-an enigma. 7 Neurol Neurosurg Psychiatry 1989;52:1185-7.

3 Goulatia RK, Verma A, Mishra NK, Ahuja GK. Disappearing CT lesions in epilepsy. Epilepsia 1987;28:523-7. 
+ Chandy MJ, Rajshekhar V, Prakash S, et al. Cysticercosis causing single small CT lesions in Indian patients with seizures. Lancet 1989-1:390-1.

Rajshekhar V, Abraham J. Disappearing CT lesions in Indian parients with epilepsy. F Neurol Neurosurg Psychiatry 1990;53:818-9.

6 Ahuja GK, Beghari M, Prasad K, Goulatia RK, Jailkham B. Disappearing CT lesions in epilepsy: is tuberculosis or cysticercosis the cause? $\mathcal{f}$ Neurol Neurosurg Psychiatry 1989;52:915.

7 Zegers De Beyl D, Hermanus N, Colle H, Goldman S. Focal scizures with reversible hypodensity on the CT scan 7 Neurol Neurosurg Psychiatry $1985 ; 48: 187-7$.

8 Feinstein A, Ron M, Wessely S. Disappearing brain lesions, psychosis and epilepsy: a report of two cases. F Neurol Neurosurg Psychiatry 1990;53:244-8. Minguetti G, Ferreira MVC. Computed tomography in neurosysticercosis I Neurol Neurosurg Psychiatry 1983;46:936-42.

(Accepted 6 February 1991)

\section{Evaluation of a diagnostic algorithm for heart disease in neonates}

\author{
Rodney C G Franklin, David J Spiegelhalter, Fergus J Macartney, Kate Bull
}

\section{Abstract}

Objective-To develop, test, and validate an algorithm for diagnosing disease in neonates during an over the telephone referral to a specialist cardiac centre.

Design-A draft algorithm requiring only data available to a referring paediatrician was generated. This was modified in the light of a retrospective review of case records. A questionnaire to elicit all the data required by the algorithm was then generated. There followed a prospective three phase evaluation during consecutive over the telephone referrals. This consisted of $(a)$ a conventional phase with unstructured referral consultations, $(b)$ a phase with referrals structured around the questionnaire but independent of the algorithm, and $(c)$ a validation phase with the algorithm (and its previous errors) available during the referral consultation.

Setting-59 paediatric centres in south east England and a central specialist paediatric cardiology unit.

Patients-Consecutive neonates (aged $<\mathbf{3 1}$ days) referred with suspected heart disease. The retrospective review was of records of 174 neonates from 1979. In the prospective evaluation (1987-90) the conventional phase comprised 71 neonates (over 5.5 months), the structured phase 203 neonates (over 14 months), and the validation phase 195 neonates (over 12 months).

Main outcome measures-Diagnostic accuracy (assigning patients to the correct diagnostic category (out of 27)), of the referring paediatrician, the specialist after the referral consultation, and the algorithm as compared with the definitive diagnosis by echocardiography at the specialist centre, and score for the appropriateness of management in transit .

Results - Simply structuring the consultation by questionnaire (that is, proceeding from the conventional phase to the structured phase) improved the diagnostic accuracy of both paediatricians (from $34 \%(24 / 71$ cases $)$ to $48 \%(97 / 203)$ correct $)$ and
Hospital for Sick Children, Great Ormond Street, London WC1N 3JH research fellow

Fergus J Macartney, FRCP, professor of paediatric cardiology

Kate Bull, MRCP, senior cardiology

MRC Biostatistics Unit, Cambridge CB2 2BW

David J Spiegelhalter, PHD, senior statistician

Correspondence and requests for reprints to: Dr Bull, thoracic unit.

BMF 1991;302:935-9
Rodney C G Franklin, MRCP, lecturer in paediatric

centre in poor condition, no matter how aggressive their subsequent management..$^{1-3}$ Ideally, appropriate management should begin at the referring hospital and continue in transit to the specialist centre, which may take several hours. ${ }^{4}$ Despite the dangers of inadequate, inappropriate, or overzealous treatment, ${ }^{56}$ however, management must usually be initiated on the basis of a presumptive clinical diagnosis, typically arrived at by a non-specialist without special training in cross sectional echocardiography (by which a definitive diagnosis is ultimately made).

District paediatricians refer the patients by telephone and discuss starting supportive treatment. We aimed at developing, testing, and validating a diagnostic aid for use during this over the telephone consultation. Its diagnostic accuracy and implications for management in transit would then be compared with conventional diagnostic and referral methods, with the aim of improving the condition of neonates arriving at specialist centres.

\section{Patients and methods}

Retrospective review-The clinical findings and provisional diagnoses of all 174 consecutive neonates who presented to the Hospital for Sick Children at under 31 days of age in 1979 were reviewed. In 1979 neither cross sectional echocardiography nor prostaglandin was available and our cardiologists made an initial diagnosis based on data comparable to those available to referring paediatricians during this study.

Conventional phase-Conventional over the telephone referrals are unstructured by questionnaires or algorithms. Prospectively, at the end of each of 71 consecutive referral conversations over 5.5 months, both the general paediatrician and the paediatric cardiologist were asked to specify a diagnosis based on the clinical findings and investigations discussed. The final diagnosis was determined by cross sectional echocardiography after the child's transfer.

\section{DIAGNOSTIC ALGORITHM}

An algorithm for diagnosing congenital heart disease correct). The algorithm (structured phase) would have been even more accurate ( $78 \%$ (158/203 cases); $\mathbf{p}<\mathbf{0 . 0 1})$. Management scores in the structured phase were also better than in the conventional phase $(80 \%(162 / 203$ cases $) v 58 \%(41 / 71)$ appropriate; $\mathbf{p}<\mathbf{0 . 0 1})$. Management scores would have improved to $91 \%$ appropriate $(185 / 203 ; \mathrm{p}<0.001)$ had the algorithmic diagnoses dictated management. The superiority of the algorithm was maintained but not bettered in the validation phase.

Conclusions-Applying the algorithm should reduce the morbidity and mortality of neonates with critical heart disease by aiding clinicians in therapeutic decisions for in transit care.

\section{Introduction}

The outcome of neonates with critical congenital heart disease is prejudiced if they arrive at a specialist aid. The algorithm required only basic clinical data available to any clinician dealing with a neonatenamely, results of a clinical examination, an electrocardiogram, chest $x$ ray appearances, and, sometimes, arterial blood gas tensions. In the light of the retrospective review this draft algorithm was amended and a series of defaults created to allow for incomplete information so that it could be run for all patients (see appendix). At this stage the algorithm, in near final form, distinguished 27 diagnostic categories, including lung disease masquerading as heart disease and disturbances of the transitional circulation.

For prospective testing a questionnaire to elicit the data required by all pathways of the algorithm was generated. The study was explained by letter to the 115 paediatricians who referred neonates to our institution, enclosing a sample questionnaire. 